\title{
A Supervisão de Estágio em Psicologia Hospitalar no Curso de Graduação: Relato de uma Experiência
}

The Hospital Psychology Probation Supervision in

Graduation Course: an Experience Relate

Universidade

do Estado do

Rio de Janeiro/

Universidade

do Estácio de Sá
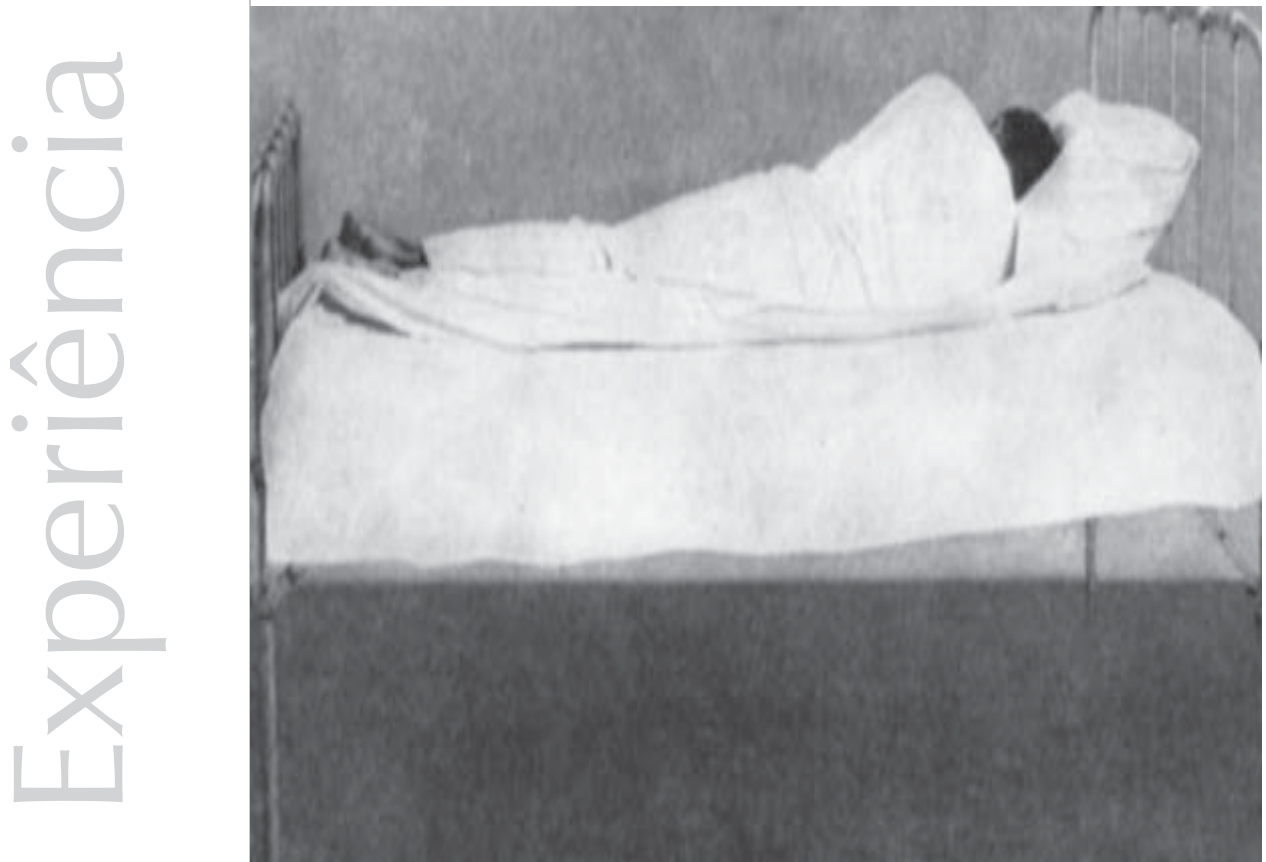
Resumo: O presente artigo tem como objetivo relatar uma experiência de supervisão de estágio em Psicologia hospitalar no curso de graduação. Para essa análise, recorreu-se à própria vivência como supervisora de estágio em uma universidade, na cidade de Resende, no Estado do Rio de Janeiro. Este relato enfocou o período de março de 2003 a julho de 2005, e foi baseado nas observações das condutas e nas falas dos estagiários durante as supervisões. Ao longo desse período, foram observados 26 (vinte e seis estagiários), que tiveram quatro grandes dificuldades durante o processo de estágio: inserção no contexto hospitalar, contato com o paciente, atuação junto aos familiares e relacionamento com a equipe de saúde. Para cada um desses impasses, foram apresentadas estratégias usadas em supervisão a fim de que esses obstáculos pudessem ser superados. Concluímos que a supervisão de estágio ocupa um papel fundamental na suplantação das dificuldades apresentadas.

Palavras-chave: supervisão, estágio, graduação, Psicologia hospitalar.

Abstract:The present paper has the objective to relate an experience in hospital Psychology supervision in the graduation course. For the analysis, we made use of our experience as a probation supervisor in a university in Resende, in the Rio de Janeiro State, Brazil. This report focused the period between March, 2003, and July, 2005, based on the conduct observations and the students' speech analysis at the supervision encounters. Along the period, 26 students were observed; they had four main difficulties during the probation process: their insertion in the hospital context, the contact with the patients, the actuation with the patient's relatives and the relationship with the health staff. For each one of those problems were presented used strategies in supervision to surpass those obstacles. We concluded that probation supervision occupies a fundamental place to solve the presented difficulties.

Key words: supervision, probation, graduation, hospital Psychology.

O presente artigo tem como objetivo relatar uma experiência de supervisão de estágio em Psicologia hospitalar no curso de graduação. Para esta análise, recorremos à própria experiência como supervisora em uma universidade na cidade de Resende, no Estado do Rio de Janeiro.

O estágio em Psicologia hospitalar, na referida universidade, tem como proposta capacitar o aluno para realizar intervenções psicológicas no Hospital Geral. A partir do $8^{\circ}$ período, o aluno possui o que denominamos de maturidade acadêmica para ingressar nos estágios em saúde, ou seja, ele cumpriu um número de disciplinas básicas para começar as suas atividades como estagiário e cursou outras que são referências teóricas fundamentais para a prática, como as disciplinas de Psicologia hospitalar e Saúde coletiva, entre outras.
O estágio em Psicologia hospitalar é opcional; o aluno tem um leque de possibilidades de escolhas tanto na área social quanto na área clínica. Na área social, são oferecidos estágios em Psicologia jurídica, Psicologia organizacional, Psicologia escolar e Psicologia da saúde coletiva (abarcando a saúde mental e a Psicologia hospitalar), por sua vez, na área clínica, tem-se a opção das seguintes linhas teóricas: psicanálise, Gestalt, fenomenológicoexistencial e cognitivo-comportamental.

Os estágios ocorrem semestralmente, e, ao fim do semestre, o aluno tem a opção de continuar mais um semestre na mesma área ou não, podendo realizar até três períodos num mesmo estágio. Trata-se de um estágio curricular e todos os estagiários devem estar devidamente matriculados nas disciplinas de estágio escolhidas. As supervisões são realizadas com um grupo de estagiários na 
própria universidade, onde os alunos relatam os atendimentos clínicos, debatem sobre os projetos referentes ao estágio, trocam as experiências e abordam as suas dificuldades e questões relacionadas à vivência na instituição. Como parte de seu processo de avaliação, o aluno deve apresentar dois trabalhos ao longo do semestre, apresentando uma articulação entre a teoria em Psicologia hospitalar e a prática no estágio. Além disso, os alunos também são avaliados através das participações em supervisão e do cumprimento da freqüência no estágio, que consiste em 8 (oito) horas semanais ao longo do semestre.

O fato de ser um estágio curricular garante a responsabilização da universidade pelo seguro do aluno no desenvolvimento de suas funções e insira-o numa instituição conveniada. A instituição em questão é um hospital público voltado para o atendimento de emergências, localizado na cidade de Resende - que possui cerca de 105.000 habitantes. O hospital possui enfermarias feminina e masculina, pediatria, centro de terapia intensiva e pronto-socorro, espaços onde os estagiários realizam as suas atividades.

\section{Metodologia}

Ao longo do período de março de 2003 a julho de 2005, foram observadas as condutas e as falas recorrentes de 26 (vinte e seis) estagiários durante as supervisões, os quais apresentaram quatro grandes dificuldades no processo de estágio: inserção no contexto hospitalar, contato com o paciente, atuação junto aos familiares e relacionamento com a equipe de saúde.

Abordamos como esses impasses podem ser trabalhados em supervisão, apresentando algumas estratégias usadas. Assim, pretendemos discutir as possibilidades e limites do ensino da Psicologia aplicado ao contexto hospitalar.

\section{Relato da experiência}

O primeiro grande nó observado é a inserção no contexto hospitalar. O aluno se depara com a realidade de saúde pública tão desconhecida ao universitário: a pobreza, a miséria, as filas para esperar atendimento são situações que os chocam profundamente. Somado a isso, têm que se deparar com o sofrimento físico do doente, o contato com a dor, o sangue, a morte e os maus odores decorrentes da doença (Chiattonne, 2000).

Apesar de esses alunos terem cursado anteriormente a disciplina de Psicologia hospitalar, onde são alertados para essas características, observamos que só têm uma real dimensão desses fatores quando iniciam o estágio. E, por vezes, é tão impactante, gera tanta frustração e temor que começam a faltar ao estágio e à supervisão. Entram num processo em que esperam ter coragem para ir novamente ao estágio para depois voltar a freqüentar a supervisão.

Esse tipo de reação é freqüentemente notado nos alunos que ingressam no estágio, e o não ir à supervisão corta a possibilidade de fala e, em conseqüência, de uma elaboração desse conteúdo. A estratégia que utilizamos para lidar com esse fato é entrar em contato com o aluno através de um telefonema ou mesmo nos corredores da universidade. O que se nota é que ele se sente mais à vontade para explanar essa situação a sós com o supervisor. Estabelecemos uma escuta inicial, mas é estimulado que isso seja colocado no grupo, até para que ele possa ouvir, de colegas que já estão no estágio há mais tempo, um relato de suas experiências, que, por vezes, se assemelharam ao que ele está passando.

Entendemos que o grupo formado por estagiários iniciantes e mais experientes é extremamente produtivo, e a cada semestre novos alunos se mesclam aos antigos. Essa é uma forma estratégica para que os recémingressos possam contar com a acessoria daqueles que já têm alguma vivência. 
O aluno, quando expõe sua resistência inicial de ir ao estágio, sente-se menos fragilizado, uma vez que ouve de seus colegas relatos parecidos e formas diferentes de se lidar com as dificuldades apresentadas. Por vezes, essa ambiguidade de sentimentos - o querer fazer estágio na área hospitalar e o não conseguir ir - é superada.

A monitoria de estágio tem-se mostrado essencial para a inserção do iniciante no contexto hospitalar. Quando começamos a trabalhar com esse sistema, introduzíamos o estagiário no Hospital Geral observando os atendimentos aos pacientes feito pelo monitor -estagiário que está no segundo semestre do estágio. Depois de alguns semestres, vimos que esse tipo de estrutura estimulava a dependência e a imitação de estilo do terapeuta. Percebemos que alguns estagiários cumpriam um semestre letivo sem que conseguissem realizar atendimentos individualmente.

Atualmente, o direcionamento assumido pela monitoria é de estimular a autonomia dos estagiários. Acredita-se que o processo de aprendizagem implica, inclusive, deixar os alunos passarem por situações desconfortáveis, como o não saber o que falar numa intervenção, suportar o silêncio do paciente, sentir-se perdido no hospital e mal fisicamente depois de algum atendimento, enfim, momentos em que a maioria dos psicólogos da área já passou e é importante permitirmos que os alunos os vivenciem também.

Hoje entendemos que o monitor deve ser uma referência, alguém que está na retaguarda e não lado a lado, que possa discutir um caso, dar uma orientação quando preciso e, sobretudo, alguém que não os poupe da realidade hospitalar.

No entanto, vemos alunos que, apesar de todas as táticas desenvolvidas para que possam adaptar-se ao trabalho nessa instituição, não estabelecem um vínculo no estágio, e, ao fim do semestre, desistem, isto é, não dão continuidade no segundo semestre de estágio. De 26 (vinte e seis) estagiários que tivemos no período mencionado, 14 (quatorze) não optaram por fazer o segundo semestre de estágio, ou seja, $54 \%$ dos alunos.

O segundo problema encontrado refere-se ao contato com o paciente, que é sempre algo diferente daquele do modelo da clínica tradicional. O espaço institucional não permite a privacidade preconizada pelo modelo clínico e tampouco os seus atendimentos duradouros. Além disso, a demanda de quem está no Hospital Geral não é o sofrimento psíquico, mas o físico (Angerami-Camon, 2001; Chiattone, 2000).

Observamos que a grade curricular nos últimos anos tem se modificado. Se, há alguns anos, a formação estava totalmente voltada para a prática privada de consultórios particulares, o mesmo não ocorre hoje. $\mathrm{O}$ aluno tem um leque de disciplinas que enfocam abordagens sociais como a instituição, a saúde, a área jurídica, o trabalho, a escola, entre outras. Entendemos que há uma adequação às demandas do mercado de trabalho, cuja prática exclusivamente clínica se encontra saturada. No entanto, ainda assim, há a permanência, no imaginário do aluno, das referências dadas pela clínica particular.

Esse talvez seja o outro grande impasse da atuação do estagiário no Hospital Geral. "Como realizar um atendimento eficaz?" "Como ser um psicólogo num ambiente onde não há nenhum tipo de privacidade e cujos atendimentos não têm continuidade?" "Como saber se estou fazendo uma intervenção psicológica ou apenas conversando com o paciente?" Essas perguntas aparecem de diferentes maneiras na fala dos estagiários e em diversos momentos de sua prática.

Partimos do princípio que o trabalho possível em Psicologia no Hospital Geral requer um desvencilhamento do padrão de atendimento
"Como realizar um atendimento eficaz?" "Como ser um psicólogo num ambiente onde não há nenhum tipo de privacidade e cujos atendimentos não têm continuidade?" "Como saber se estou fazendo uma intervenção psicológica ou apenas conversando com o paciente?" 
O estagiário que não consegue romper como modelo clínico tradicional tem dificuldades em abordar os familiares; normalmente, os seus atendimentos são exclusivamente centrados no paciente.
Clínico tradicional; é necessário romper com essas referências, sobretudo em relação à espacialidade e à temporalidade. Essa ruptura requer um constante exercício de reflexão na supervisão; ela só passa a fazer sentido quando o aluno consegue pensar a sua atuação como contextualizada numa instituição com características particulares e com objetivos próprios.

As pessoas encaminham-se para o hospital por razões aleatórias à sua vontade, por uma urgência física, e a cura orgânica é a sua meta. Desse modo, a Psicologia não pode negar esse contexto e deve trabalhar tendo-o como parâmetro; assim, a nossa intervenção bordeia o processo de hospitalização e de adoecimento (Romano, 1999; Chiatone, 2001). Acreditamos que esse referencial possa colaborar na condução dos atendimentos dos estagiários e auxiliá-los nos seus instrumentos técnicos e metodológicos de atuação.

Pensamos que as discussões em grupo são ricas, as pontuações do supervisor também são válidas, mas ainda não são suficientes para que o aluno suplante o modelo clínico tradicional. Para isso, devemos utilizar outros instrumentos na supervisão, como a leitura de livros da área, e, especialmente, a produção de trabalhos visando à articulação teoria/ prática e à formulação de projetos. O aluno, ao produzir um texto, pode melhor organizar seu pensamento e elaborar as questões relativas à atuação no contexto hospitalar.

Notamos claramente quando o estagiário já incorporou os paradigmas da Psicologia hospitalar; falas como: "eu fiz um acompanhamento desse paciente com começo, meio e fim", "atendi o paciente como se fosse a primeira e a última vez", revelam que houve assimilação de outras abordagens diferentes da clínica privada. Mas, apesar disso, há casos de alunos que não conseguem suplantar o modelo clínico de consultório e estabelecem uma relação com os atendimentos no hospital marcada por frustrações, o que acreditamos seja uma das razões que os leva a interromper o estágio quando finda o primeiro semestre.

O acompanhamento aos familiares é o terceiro ponto delicado no estágio de Psicologia hospitalar. A família, ao receber a notícia da doença e/ ou hospitalização de um de seus membros, desequilibra-se, podendo até mesmo desenvolver algum tipo de patologia em decorrência do estresse (Romano,1999). Dessa forma, deve ser assistida e acompanhada pelo psicólogo. Ela é importante para nos dar informações sobre o paciente e também como objeto de nossa intervenção. Romano (1999), ressalta que, muitas vezes, a desestrutura do grupo familiar é tão grande que não conseguem entender os procedimentos do hospital e tampouco as informações dadas sobre o tratamento de seu parente. Nesse caso, é importante que o psicólogo esteja atento a essa dinâmica e indique à equipe médica qual seria a pessoa da família mais centrada para receber as instruções diagnósticas e terapêuticas.

O estagiário que não consegue romper com o modelo clínico tradicional tem dificuldades em abordar os familiares; normalmente, os seus atendimentos são exclusivamente centrados no paciente. A estratégia usada na supervisão, além das já citadas acima, é incentivá-lo a ir nos horários de visita, onde poderá deparar-se com diversos grupos de familiares. Para aqueles que se intimidam com essa sugestão, pedimos apenas que estejam no local e se apresentem dizendo que são estagiários de Psicologia, que estão à disposição se necessitarem falar sobre o momento de hospitalização e a doença de seu parente. Entendemos que, se o aluno conseguir abrir esse canal de comunicação, um segundo passo pode até mesmo partir da família do doente. O ambiente hospitalar é, muitas vezes, hostil; as relações humanas são deixadas em segundo plano e, geralmente, os familiares estão tão desamparados que a possibilidade de alguém oferecer sua escuta 
já é o suficiente para que eles queiram expressar-se, falar sobre o momento vivido.

Durante a nossa vivência na supervisão, pudemos presenciar algumas iniciativas dos estagiários que revelam a consciência da importância desse tipo de trabalho. Alguns alunos vêm desenvolvendo um acompanhamento aos familiares de pacientes do CTI, e a abordagem acontece no corredor, durante o momento em que aguardam para ver o parente hospitalizado ou mesmo quando estão esperando o parecer médico. Também foram desenvolvidas intervenções expressivas com famílias na pediatria e nas enfermarias do hospital. Mas, apesar das táticas em supervisão, há aqueles estagiários que focalizam a atenção quase que exclusivamente nos pacientes, reproduzindo um modelo clínico tradicional e negando as especificidades do contexto no qual estão inseridos. Geralmente, esse aluno não dá continuidade ao estágio por não conseguir adaptar-se às demandas institucionais.

O relacionamento com a equipe de saúde é o quarto aspecto gerador de impasses para o aluno. Acreditamos que esse tema possa ser mais ou menos polêmico dependendo da inserção da Psicologia no Hospital Geral. Há relatos de psicólogos que demonstram a Psicologia efetivamente fazendo parte da equipe interdisciplinar, sendo solicitada pelos médicos para realizarem atendimentos e desenvolverem trabalhos com os demais profissionais - grupos Balint, estudos de casos (Romano, 1999).

Na instituição conveniada, havia apenas uma psicóloga, que tinha que responsabilizar-se por toda a demanda hospitalar, e, no início do ano de 2005, foi contratada mais uma profissional de Psicologia; esta havia sido nossa estagiária em Psicologia hospitalar. Talvez esse excesso de atribuições por tanto tempo direcionado a praticamente uma psicóloga tenha sido um dos fatores que fizeram com que a Psicologia, em um âmbito geral, fosse praticamente inexpressiva nesse hospital. Não há uma sala para guardar os pertences, nem material de trabalho - caixa de brinquedos para atendimento de crianças e relatório de atendimento psicológico.

Desde a nossa entrada, em 2003, os estagiários tiveram uma tarefa implícita, conquistar um "lugar" para a Psicologia na instituição. Assim, o estagiário é estimulado semanalmente a realizar trocas com a equipe de saúde: psicóloga, enfermeiros, assistentes sociais, nutricionistas, médicos e também os funcionários de apoio (recepcionistas, cozinheiros e faxineiros). Um atendimento eficaz no hospital geral não pode dar-se sem essa rede de pessoas que estão envolvidas com o paciente.

O que notamos é que, com a equipe, à exceção dos médicos, conseguiu-se estabelecer uma comunicação, embora ainda haja dificuldades. É importante ressaltar que, quando nos referimos a dificuldades, não significa que se refiram exclusivamente ao relacionamento entre estagiários e equipe, mas às próprias características da saúde pública no Brasil: funcionários insatisfeitos com salários e excesso de trabalho. Talvez esse seja um dos motivos que fazem com que nem sempre os profissionais se mostrem receptivos e dispostos ao diálogo. Mas, de modo geral, o estagiário consegue estabelecer um bom rapport com eles.

O grande impasse ainda é o profissional de Medicina. Como os médicos da instituição muitas vezes não se mostram abertos para a troca, o aluno se ressente, e é muito comum sentir-se acuado, intimidado diante deles.

Podemos dizer que a formação médica é completamente distinta da do psicólogo; ambos se encontram em paradigmas totalmente distintos, e, portanto, possuem objetos de trabalho e visões de mundo diferentes (Moretto, 2001). O médico é formado para exercer uma medicina anátomo- 
clínica, e procura estabelecer uma relação entre órgão lesado e doença (Foucault, 2001). Isso faz com que sua prática seja empírica e baseada num conhecimento objetivo estruturado nas ciências biológicas. $\mathrm{O}$ seu foco é a doença, e não o doente. Dessa forma, todos os referenciais que fogem a esse padrão, como os aspectos psíquicos e sociais do paciente, são considerados desnecessários e meras especulações metafísicas (Camargo Jr, 2003). Por sua vez, a Psicologia, de uma forma geral, é construída sobre um objeto não palpável e invisível, a subjetividade.

Essa reflexão faz-se necessária em supervisão, e estudar sobre aspectos epistemológicos e históricos da Medicina auxilia a compreender as relações atuais entre médicos, pacientes e demais profissionais. Além disso, é preciso incentivar no estagiário a comunicação com o médico sem que isso seja feito de forma submissa. É interessante que ele peça informações e esclarecimentos sobre procedimentos médicos e medicamentosos acerca do paciente, e que, assim, possa deixar uma abertura para que o profissional de Medicina também esclareça questões relativas aos aspectos psicológicos do doente.

O estagiário mostra-se muito reticente em tomar a iniciativa de abordar o médico; algumas vezes, ouvimos em supervisão: "nós não precisamos perguntar ao médico, podemos ver essas informações no prontuário do paciente". Apesar de frases semelhantes a essas serem freqüentes no estagiário, vemos que há movimentos de aproximação de ambas as partes que são, por vezes, tímidos, mas atualmente há médicos e outros membros da equipe que solicitam ao estagiário de Psicologia atendimento ao paciente e valorizam o trabalho psicológico junto ao doente.

Observamos que o estagiário tem colaborado na assistência da instituição; os alunos já foram solicitados pela direção a apresentarem uma palestra a todos os funcionários sobre humanização hospitalar. Essa apresentação foi discutida e ensaiada em supervisão e teve a participação de todos os estagiários de Psicologia. Também implementamos um trabalho de humanização na pediatria hospitalar, onde, através de doações, os estagiários coordenaram intervenções no espaço físico. Essa iniciativa mobilizou sensivelmente os funcionários da instituição. Enquanto as transformações na pediatria iam ocorrendo, a equipe de saúde e técnicos iam conversar com os estagiários, relatavam o quanto o espaço estava agradável, chegavam a levar lanches e frutas, fazendo do espaço um local de trocas interpessoais.

Essas conquistas junto à equipe tem ocorrido de forma lenta, e há períodos em que se tornam maiores e, em outros, mais difíceis.

\section{Considerações finais}

Com este relato, não pretendemos oferecer um modelo para as supervisões de Psicologia hospitalar nas graduações, até porque entendemos que padrões universalizantes são sempre complicados, uma vez que desconsideram as singularidades regionais, culturais e sociais.

Nosso intuito foi oferecer um relato sobre a supervisão de estagiários em um curso de graduação que possui convênio com uma determinada instituição pública. Ao fazer essa consideração, estamos levando em conta que o nosso trabalho possui especificidades e que estas não podem ser generalizadas. Mas, ainda assim, entendemos que podemos colaborar para a reflexão da prática supervisionada de Psicologia hospitalar em universidades. Talvez as dificuldades dos estagiários expostas nesse texto, assim como algumas estratégias de enfrentamento, possam ser identificadas em alguns outros grupos.

Através dessas linhas, pudemos deparar-nos com as dificuldades mais recorrentes de alguns 
estagiários no Hospital Geral, assim como com as nossas formas de lidar com elas. Não pensamos em encerrar esse debate, e sim, incitar novos pensamentos sobre essa prática nos espaços universitários.

A formação do psicólogo se dá num tripé: estudo teórico - análise pessoal - supervisão, e, desse modo, há que se indagar sobre qual o tipo de trabalho que nós, professores e supervisores, estamos realizando.

Podemos considerar que a supervisão de Psicologia hospitalar aparece como um instrumento essencial para a formação dos alunos e para superar as dificuldades comumente apresentadas no estágio. Através da prática supervisionada, é possível reverter impasses e fazer possível um trabalho que, por vezes, se mostrava quase impossível. No entanto, tivemos a preocupação de demonstrar que, em cada dificuldade que pode ser superada com estratégias específicas, há alunos que não conseguem suplantá-las. No nosso caso, vimos que, de 26 (vinte e seis) estagiários que tivemos nesse período, 12 (doze) fizeram dois semestres de estágio, e 14 (quatorze) optaram por realizar apenas um semestre, isto é, $46 \%$ optaram por dar continuidade ao processo de estágio e 54\% decidiram finalizá-lo em apenas um semestre. A partir disso, não devemos cair no engodo da onipotência, pensando que tudo pode resolver-se através de boas intervenções junto aos estagiários. Temos inúmeras possibilidades que devem ser exaustivamente discutidas, mas também temos impossibilidades. São os limites da supervisão que devem ser vistos e reconhecidos como tal.
Carla Ribeiro Guedes

Professora da Universidade Estácio de Sá-RJ Doutoranda e Mestre em Saúde Coletiva - Instituto de Medicina Social - UERJ Rua Cinco de Julho, 188/ 304 - Copacabana- Rio de Janeiro - cep: 22051-030 E-mail: carla.guedes@globo.com Tel.: (21) 2255-2513 (21) 8748-3609

Recebido 06/10/05 Reformulado 29/03/06 Aprovado 06/06/06

ANGERAMI-CAMON, V. A. Psicologia Hospitalar: Teoria e Prática. São Paulo: Pioneira, 2001.

CAMARGO Jr., K. R. (Ir)Racionalidade Médica: os Paradoxos da Clínica. Biomedicina, Saber \& Ciência: uma Abordagem Crítica. São Paulo: Editora Hucitec, 2003.

CHIATTONE, H. B. A Significação da Psicologia no Contexto Hospitalar. Psicologia da Saúde: um Novo Significado para a Prática Clínica. São Paulo: Pioneira, 2000.
FOUCAULT, M. O Nascimento da Clínica . Rio de Janeiro: Forense Universitária, 2001

MORETO, M. L. T. O que Pode um Analista no Hospital ? São Paulo: Casa do Psicólogo, 2001.

ROMANO, B. Princípios para a Prática Clínica em Hospitais. São Paulo: Casa do Psicólogo, 1999.
Referências 